\title{
Medical Image of the Week: Pulmonary Mycetoma
}

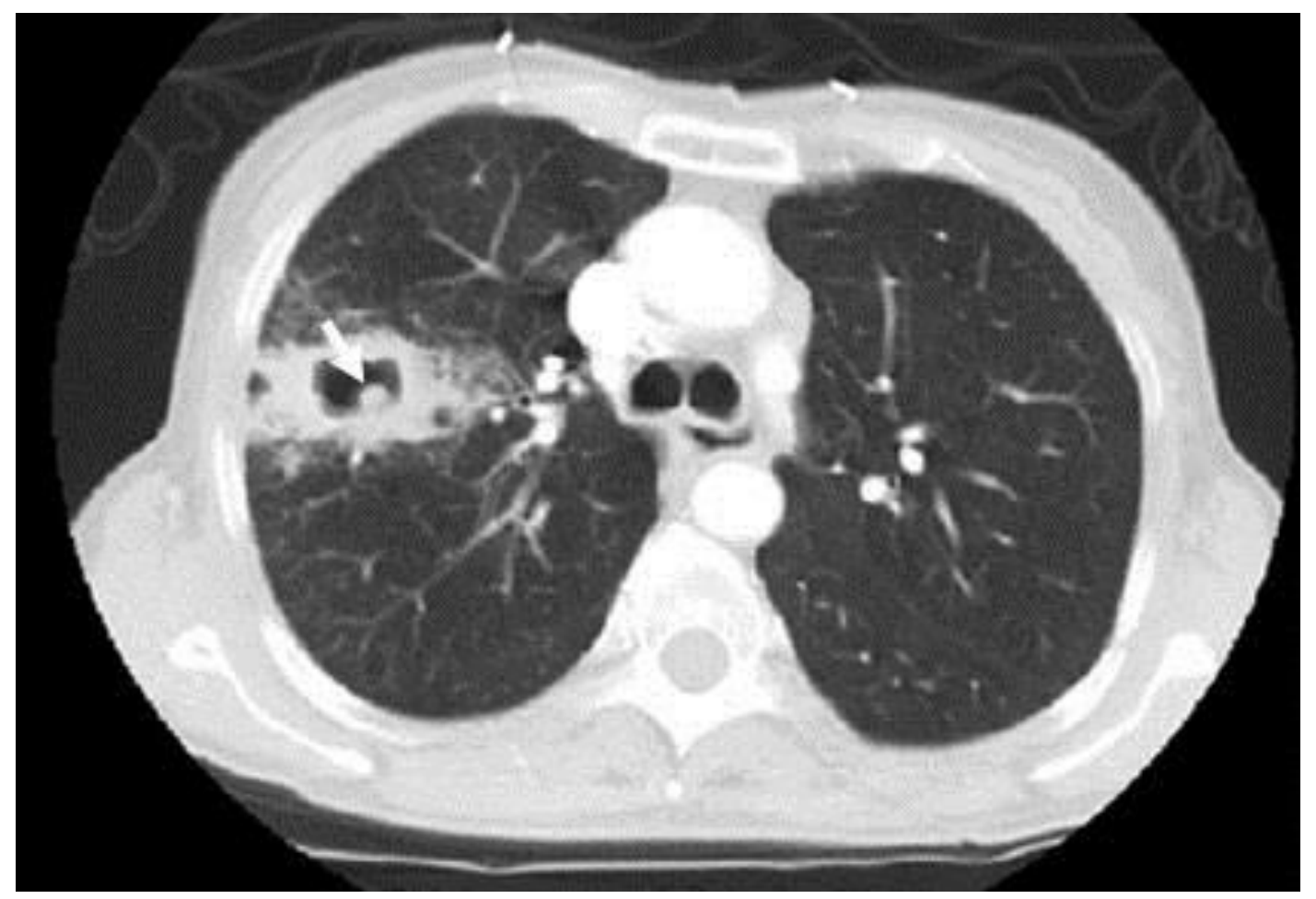

Figure 1. Thoracic CT scan showing mycetoma (arrow) in cavitary lesion in right upper lobe.

A 59 year-old woman presented with right sided chest pain and worsening shortness of breath. On CT of the chest she was found to have cavitary lesions in her right lung with one of them having a distinct opacity within the lesion concerning for a pulmonary mycetoma (Figure 1, arrow). Most literature describes pulmonary mycetomas occurring due to Aspergillus species. However, in our patient, neither the bronchoscopy with bronchoalveolar lavage (BAL) nor serological studies tested positive for Aspergillus. Cultures did however grow Candida albicans in 2 of the samples from the BAL. Mycetoma due to Candida has been described in the urinary tract in immunocompromised patients and, uncommonly, in the lung (1-3). Our patient had been treated for Stage III ovarian cancer with chemotherapy and at presentation her absolute neutrophil count was reduced at 860 . In the hospital, she was treated for her shortness of breath with albuterol-ipratropium nebulizations to which she responded well. She was discharged once stable to follow up as outpatient for further treatment of her Candida albicans mycetoma.

Saud Khan, MD and Huzaifa A. Jaliawala, MD Internal Medicine University of Oklahoma Health Sciences Center Oklahoma City, OK USA 


\section{References}

1. Praz $V$, Burruni $R$, Meid $F$, Wisard $M$, Jichlinski $P$, Tawadros $T$. Fungus ball in the urinary tract: A rare entity. Can Urol Assoc J. 2014 Jan-Feb;8(1-2):E118-20. [CrossRef] [PubMed]

2. Song Z, Papanicolaou N, Dean S, Bing Z. Localized candidiasis in kidney presented as a mass mimicking renal cell carcinoma. Case Rep Infect Dis. 2012;2012:953590. [CrossRef] [PubMed]

3. Bachh AA, Haq I, Gupta R, Varudkar H, Ram MB. Pulmonary candidiasis presenting as mycetoma. Lung India. 2008 Oct;25(4):165-7. [CrossRef] [PubMed] 